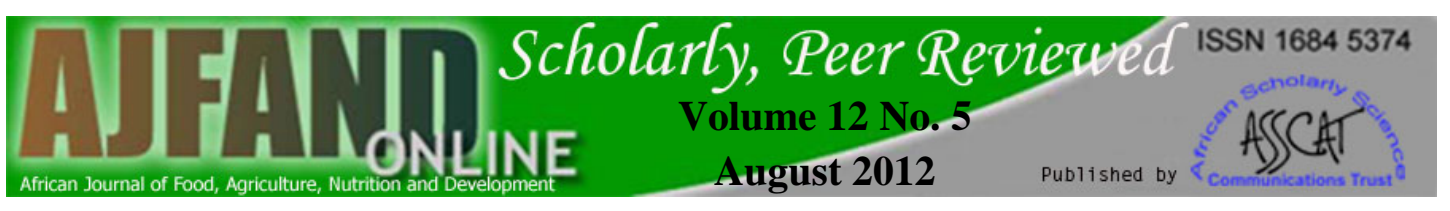

\title{
DETERMINANTS OF FAST FOOD CONSUMPTION IN KAMPALA, UGANDA
}

\section{Ayo $\mathrm{SA}^{1}$, Bonabana-Wabbi $\mathrm{J}^{{ }^{*}}$ and D Sserunkuuma ${ }^{1}$}
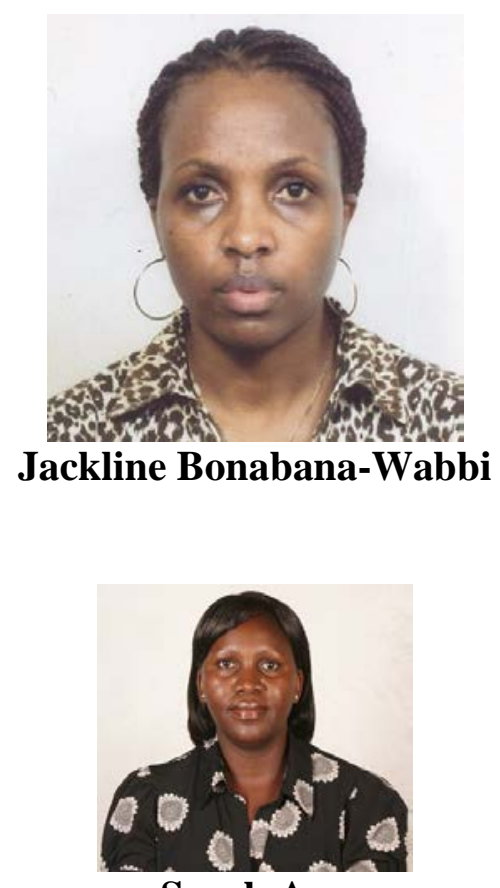

Sarah Ayo

*Corresponding author email: jbexim@gmail.com

${ }^{1}$ Department of Agribusiness and Natural Resource Economics, Makerere University P.O. Box 7062 Kampala, Uganda 


\section{ABSTRACT}

Consumption of fast-food in Uganda is becoming an increasingly important component of the food market as more of the working class choose to dine out rather than prepare meals at home. Despite the importance of the fast-food sector, limited attempts have been made to study the consumption and expenditure behaviour of consumers of fast-food in Uganda. The main objective of this study was to assess characteristics influencing the consumption of fast-food in Kampala district. Specifically, the objectives of the study were: to assess the factors influencing the probability of consuming fast-food; and to determine the level of expenditure on fastfood. Primary data on socio-economic characteristics were collected from a sample of 300 respondents using a multi-stage sampling procedure. The study revealed that majority (90\%) of the respondents consumed fast-food. The consumption of fast-food was most motivated by their taste and convenience. Results from the Heckman model show that household size, education level and distance from work-place to restaurant negatively influenced the probability of fast-food consumption and level of expenditure on fast-food while disposable monthly income had a positive effect on the probability of consumption and level of expenditure on fast-food. The high demand for fast-food is seen as an easy solution to consumers' busy schedules and limited meal preparation time. As changing tastes and need for convenience become the goal of households, consumption of fast-food will be expected to rise especially in urban areas. This increase in fast-food consumption, coupled with rising population and urbanization in Uganda offers new market opportunities for agribusiness firms to exploit the growing demand by investing in the fast-food sector and producing sufficiently for this market. In addition, fast-food establishments should ensure proximity of their products and services to the consumers as convenience greatly influences fast-food consumption. Future research should include identification of sources of agricultural products used by fast-food outlets to provide information about the contribution of the fast-food sector to agricultural marketing and farmers' livelihoods in Uganda.

Key words: Fast-food consumption, Heckman model, Uganda 


\section{INTRODUCTION}

Global food consumption patterns have dramatically changed in recent years. One common consumption pattern that is shared by many countries is the increasing expenditure on food away from home (FAFH). This is evident in the growth of the FAFH market segment which has become very popular in recent years [1, 2]. The fast-food outlets have, however, surpassed the full-service restaurants as the main source of the FAFH [3]. Many scholars have attributed the growth in the FAFH market to a number of socio-economic/demographic factors such as income, age, urbanization, gender, household size and composition, time value, education level, distance from restaurants to work place and occupation, among others. For instance, Ekelund and Watson [4], Jekanowski et al. [5], Stewart and Yen [6], Matthews [7] and Akbay et al. [8] all identified household income as an important determinant of household expenditure on FAFH. Specifically, Ekelund and Watson [4] found that fast-food consumption was empirically related to opportunity cost of the household. Jekanowski et al. [5] noted that the growth in FAFH was due to fast-food companies building more outlets closer to where people work.

Fast-food, as defined in this study is food that is readily available for consumption within the premise (s) or to be carried away. Despite the growing concern on consumer health $[9,10,11]$, the fast-food industry in Uganda has grown in the past decade as evidenced by the emergence of multinational fast-food outlets like Nandos, Dominos Pizza Inn and Steers and continues to attract more proprietors like fast-food outlets in new shopping malls/supermarkets especially in the urban settings [12]. With a changing lifestyle and population growth in Kampala (estimated at 1.66 million in 2010 mid year from 1.2 million people in 2002 [13] and the growing number of high value markets like fast-food outlets and supermarkets, fast-food consumption is expected to increase in urban areas [14]. This trend suggests that the success of existing fast-food outlets and entry of more is inevitable. Thus, the increasing consumption of fast-food and number of fast-food outlets calls for increased investment in the production of both agricultural products (raw materials used in the production of fast-food products) and the fast-food products. Consumption patterns keep changing thus affecting the availability and access to food through changes in agricultural production, procurement and distribution systems [15]. This, however, requires knowledge of the behaviour of consumers who eat away from home.

Given this change in food consumption patterns, there is need to assess the characteristics underlying the consumption of fast-food as a means of informing Agribusiness enterprises on how best to gainfully exploit this growing demand.

The understanding of these factors (consumer characteristics) will be pertinent for proper assessment of the agricultural product market opportunities in Uganda. That is, by identifying characteristics of consumers and fast-food products desired by the consumers of fast-food, agribusiness firms can design appropriate programmes to promote the production and distribution of fast-food products to meet this demand. In addition, the government can design appropriate policies to promote the production and distribution of agricultural products that can be used to make fast-food products.

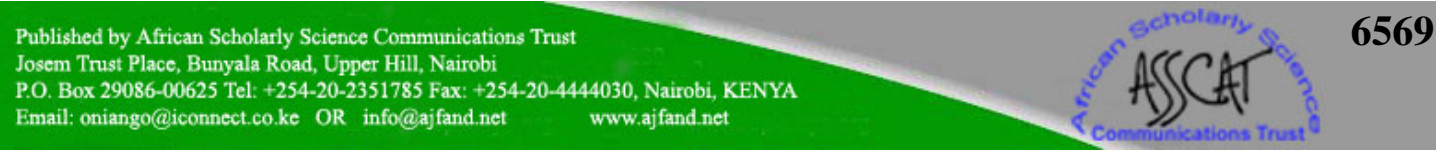


Whereas researchers outside Uganda have studied factors affecting fast-food consumption, few studies in Uganda have been done on fast-food and more so, factors influencing fast-food consumption have not been studied. For instance, Kayemba [12] studied the growth and development of fast-food outlets in Kampala; Nakalungi [16] studied the challenges of running fast-food services in a vibrant food industry; Nambaziira [17] studied the importance of fast-food to the development of the Tourism industry; and Namawejje [18] studied the spatial distribution and development of restaurants and takeaways in the provision of fast-food in Jinja town. This study on the determinants of fast-food consumption in Kampala district is the first of its kind in Uganda.

The main objective of this study was to assess factors influencing the consumption of fast-food in Kampala district. The specific objectives of the study were to assess the factors influencing the probability of consuming fast-food; and to determine the level of expenditure on fast-food.

\section{METHODOLOGY}

\section{Study area, sample and data}

Kampala district, the capital city of Uganda is bordered by Wakiso and Mukono districts. It is divided into five divisions namely; Central, Nakawa, Kawempe, Makindye and Rubaga. Primary data were collected from a sample of 300 respondents using a multi-stage sampling procedure from three divisions namely Central, Kawempe and Nakawa. Data collected through face-to-face interviews by use of pretested questionnaires included respondents' age, gender, occupation, education level, income, time spent away from home, distance from work place to restaurant, household size, marital status, types of fast-food and reasons for consumption and non-consumption of fast-food.

\section{Model Specification and Estimation}

The Heckman's two-step estimation (Heckit) procedure was applied in this study as suggested by Heckman [19, 20]. Step one is where the probit regression was computed to give the estimated probability that a given household participates in fastfood consumption. This regression was used to estimate the Inverse Mills Ratio (IMR) for each household, which was then used in the second (expenditure) regression. The probit model used to study data with binomial distributions is as follows: Assuming the decision to consume fast-food or not depends on unobserved utility index $\boldsymbol{I}_{\boldsymbol{i}}$ (latent variable) that is determined by explanatory variables $x_{i}$ such that the larger the value of the index the greater the probability of the household consuming fast-food. The index can be expressed as: $I_{i}=x_{i} \beta_{i}$, where $x_{i}$ is a vector of exogenous variables. Let $Y_{i}=1$ if the household consumes fast-food and $Y_{i}=0$ if it doesn't. Assume there is a threshold level of the index say; $I_{i}^{\bullet}$ such that if; $I_{i}>I_{i}^{\bullet}$ then the household consumes fast-food, otherwise it will not. $I_{i}^{\bullet}$ like $\boldsymbol{I}_{i}$ is not observable. However, assuming that it is normally distributed with the same mean and variance, the parameters of the index can be estimated as:

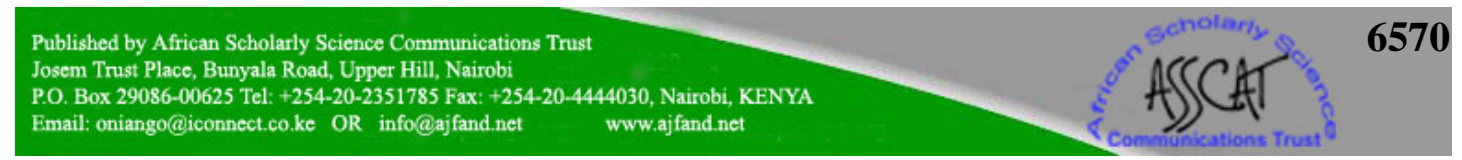


$P_{i}=P(Y=1 / x)=P\left(I_{i}^{\cdot} \leq I_{i}\right)=P\left(Z_{i} \leq x_{i} \beta_{i}\right)$, thus

$P=F\left(x_{i} \beta_{i}\right)$

Where $P_{i}=P(Y=1 / x)$ is the probability of participation given the explanatory variables $x_{i}$

$Z$ is the standard normal variable and is normally distributed as $\sim N\left(0, \sigma^{2}\right)$

$F$ is the standard normal CDF (Cumulative Distribution Function)

Step two involved estimation of expenditure levels on fast-food expressed as:

$E\left(Y_{i} / Y_{i}>0\right)=\alpha w_{i}+f\left(\beta x_{i}\right) / F\left(\beta x_{i}\right)$

Where $E$ = Levels of expenditure on fast-food in Uganda shilling (UGX)

$\alpha=$ vector of variable coefficients to be estimated

$w=$ vector of independent variables

$f$ is the density probability function and $F$ is the cumulative normal probability distribution function. The ratio $f\left(\beta x_{i}\right) / F\left(\beta x_{i}\right)$ is the $\operatorname{IMR}(\lambda)$.

The underlying assumption under the two-stage model is that the error terms of the two-equations are jointly normally distributed [19], and thus should be estimated with some explanatory variables appearing only in the binary response equation (the probit) to improve the identification of the model [21]. However, theory provides no guidance as to which explanatory variables are included in the first and second equations, thus exclusion restrictions were imposed [7]. In this case the variables with correlations due to the spurious effect were dropped from the second equation. In addition, the model is identified by the functional form basing on a priori information. Income squared was included in the analysis to capture the possibility of a non-linear relationship between income and expenditure on fast-food.

The probit (participation) model estimated was specified as:

$Y_{i}=\beta_{0}+\beta_{1} X_{1}+\beta_{2} X_{2}+\beta_{3} X_{3}+\beta_{4} X_{4}+\beta_{5} X_{5}+\beta_{6} X_{6}+\beta_{7} X_{7}+\beta_{8} X_{8}+\beta_{9} X_{9}+e$

Where $Y=$ Probability of consuming fast-food (1= fast-food consumption and 0

$=$ otherwise)

$\beta_{0} \quad=$ Intercept

$X_{1} \quad=$ Disposable monthly income (UGX)

$X_{2} \quad=$ Age (Years)

$X_{3} \quad=$ Household size (Number of family members)

$X_{4} \quad=$ Education level (Years spent in school)

$X_{5} \quad$ = Occupation ( 1 = Formally employed, $0=$ Otherwise $)$

$X_{6} \quad=$ Distance from work place to restaurant (Kilometres)

$X_{7} \quad=$ Gender $(1=$ Female, $0=$ Male $)$

$X_{8} \quad=$ Time spent away from home (Hours)

$X_{9} \quad=$ Marital status ( $1=$ Married, $0=$ Otherwise $)$

$\beta_{1-9}=$ Coefficients associated with the independent variables

e $\quad=$ Error term 
The expenditure model was specified as:

$E_{i}=\alpha_{0}+\alpha_{1} w_{1}+\alpha_{2} w_{2}+\alpha_{3} w_{3}+\alpha_{4} w_{4}+\alpha_{5} w_{5}+\alpha_{6} w_{6}+\alpha_{\lambda} \lambda_{i}+\varepsilon$

Where $E_{i} \quad=$ Level of expenditure on fast-food (UGX)

$\alpha_{0} \quad=$ Intercept

$w_{1} \quad=$ Distance from work place to restaurant (Kilometres)

$w_{2} \quad=$ Household size (Number of family members)

$w_{3} \quad=$ Education Level (Years spent in school)

$w_{4} \quad=$ Disposable monthly income (UGX)

$w_{5} \quad=$ Income squared (UGX)

$w_{6}=$ Gender $(1=$ Female, $0=$ Male $)$

$\alpha_{1-6}=$ Coefficients associated with the independent variables

$\alpha_{\lambda} \quad=$ Coefficient associated with the $\operatorname{IMR}(\lambda)$

$\varepsilon \quad=$ Error term

$\lambda=$ Inverse Mills Ratio calculated from the probit results of the first step

Using data from consumers only, the Ordinary Least Square (OLS) model with IMR included as a regressor was estimated to determine the impact of the independent variables on the level of fast-food expenditure.

\section{Data analysis}

Primary data was analyzed using STATA statistical package. Test for normality was carried out to ensure that the variables were normally distributed. The Heckman model was applied to analyze both the probabilities and levels of expenditure on fastfood. Correlation matrix (Table 4) was generated and a path analysis carried out to demonstrate the effect of interaction of variables.

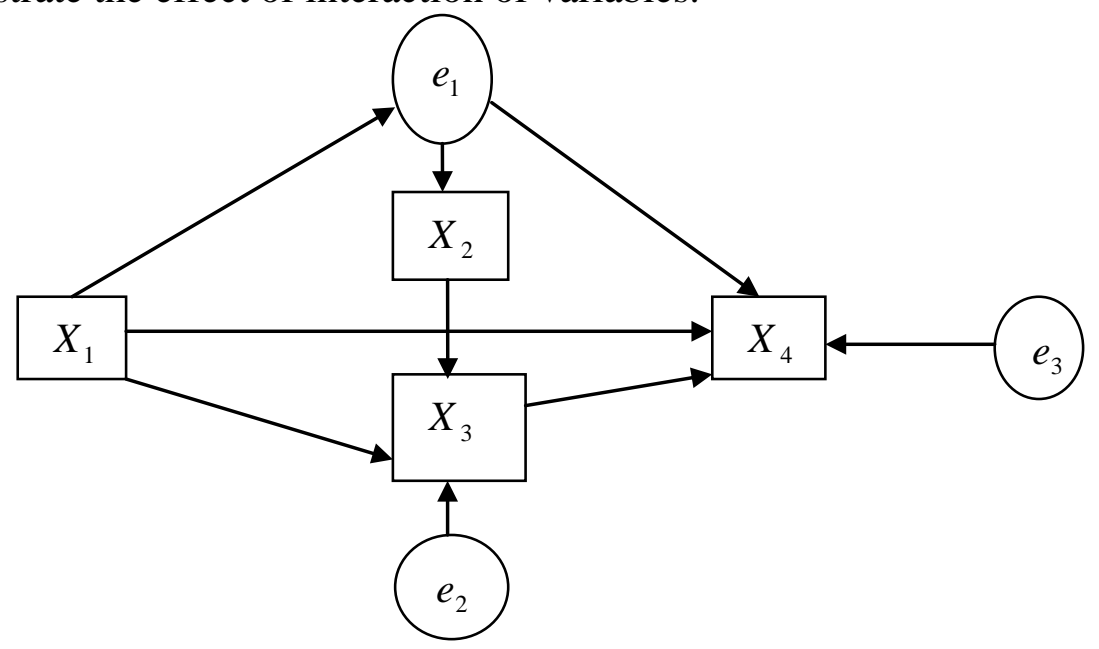

\section{Figure 1: Path Analysis}

In the calculation of path coefficients (which are equivalent to beta weights) the variables and their respective error terms follow the standard normal distribution assumption, hence each variable has a mean of $1 E\left(X_{i}{ }^{2}\right)$ and is uncorrelated with its 
error term implying that $E\left(X_{i}, e_{i}\right)=0$. Where $X_{i}$ and $e_{i}$ are variables1-4 and their respective error terms.

Taking an example of variable $X_{2}$ with a structural equation; $X_{2}=\beta_{21} X_{1}+e_{1}$. Multiplying both sides of the structural equation by $X_{1}$ gives the normal equation $X_{1} X_{2}=\beta_{21} X_{1}^{2}+X_{1} e_{1}$. Multiplying the normal equation by the expectations $(E)$ gives:

$$
\begin{gathered}
E\left(X_{1} X_{2}\right)=\beta_{21} E\left(X_{1}^{2}\right)+E\left(X_{1} e_{1}\right) \\
r_{12}=\beta_{21} x 1+0=\beta_{21}
\end{gathered}
$$

The equations for the four variables are:

$r_{12}=\beta_{21}$. $=P_{21}=0.51$ (see correlation matrix, Table 4), where $P_{21}$ is the path coefficient (path to $X_{2}$ from $X_{1}$ ). Thus, the association between $X_{1}$ (age) and $X_{2}$ (marital status) is causal. $r_{12}$ is due to a single path that indicates a direct effect.

Following the above procedure for $X_{3}$ and $X_{4}$ :

$r_{13}=\beta_{31}+\beta_{32} \beta_{21}=0.52$ indicating two causes of correlation between $X_{1}$ and $X_{3}$ ie a direct effect of $X_{1}$ on $X_{3}$ represented by $\beta_{31}$ and an indirect effect of $X_{1}$ operating through $X_{2}$ represented by $\beta_{32} \beta_{21}$.

Similarly;

i) $r_{23}=\beta_{31} \beta_{21}+\beta_{32}=0.93$. The correlation between $X_{2}$ and $X_{3}$ is due to a direct effect of $X_{2}$ on $X_{3}$ represented by $\beta_{32}$ and a spurious effect ie correlation due to a common cause $X_{1}$ represented by $\beta_{31} \beta_{21}$.

ii) $\quad r_{14}=\beta_{41}+\beta_{42} r_{12}+\beta_{43} r_{13}=\beta_{41}+\beta_{42} \beta_{21}+\beta_{43}\left(\beta_{31}+\beta_{32} \beta_{21}\right)=-7,989.85$. The sources of correlation between $X_{1}$ and $X_{4}$ is due to a direct effect of $X_{1}$ on $X_{4}\left(\beta_{41}\right)$ and an indirect effect of $X_{1}$ on $X_{4}$ represented by $\beta_{42} \beta_{21},\left(\beta_{43} \beta_{31}\right)$ and $\beta_{43} \beta_{32} \beta_{21}$.

iii) $r_{24}=\beta_{41} r_{12}+\beta_{42}+\beta_{43} r_{23}=\beta_{41} \beta_{21}+\beta_{42}+\beta_{43}\left(\beta_{32}+\beta_{31} \beta_{21}\right)=-15,150.36$. The sources of correlation between $X_{2}$ and $X_{4}$ is due to a direct effect of $X_{2}$ on $X_{4}\left(\beta_{42}\right)$, an indirect (spurious) effect represented by $\beta_{43} \beta_{32}, \beta_{41} \beta_{21}$ and $\beta_{43} \beta_{31} \beta_{21}$.

iv) $r_{34}=\beta_{41} r_{13}+\beta_{42} r_{23}+\beta_{43}=\beta_{41}\left(\beta_{31}+\beta_{32} \beta_{21}\right)+\beta_{42}\left(\beta_{32}+\beta_{31} \beta_{21}\right)+\beta_{43}=-$ 14,697.57. The sources of correlation between $X_{3}$ and $X_{4}$ is due to a spurious effect represented by $\beta_{41} \beta_{31}$,

$\beta_{41} \beta_{32} \beta_{21}, \beta_{42} \beta_{32}, \beta_{42} \beta_{31} \beta_{21}$ and the direct effect represented by $\beta_{43}$.

Let $X_{1}, X_{2}, X_{3}, X_{4}$ as discussed above represent; (i) age, marital status, household size and fast-food expenditure respectively as the first set of variables. Following the same procedure with other sets of variables such as:

ii) Marital status, household size, education and fast-food expenditure, respectively.

iii) Occupation, education, income and fast-food expenditure, respectively.

iv) Time, household size, income and fast-food expenditure, respectively. Most of the correlations in each of the variable set were due to the spurious effect of variable $X_{1}$ which in this case is age, marital status, occupation and time spent away from home, thus, were dropped from the second equation.

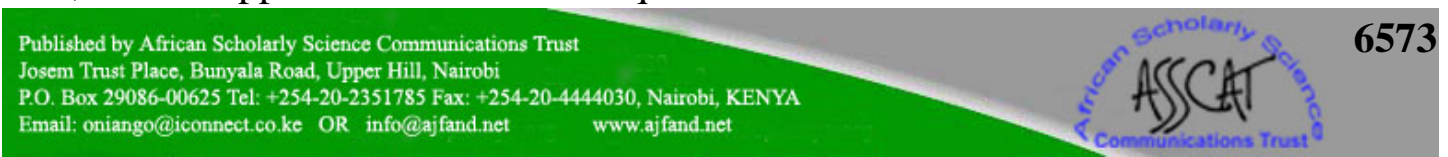




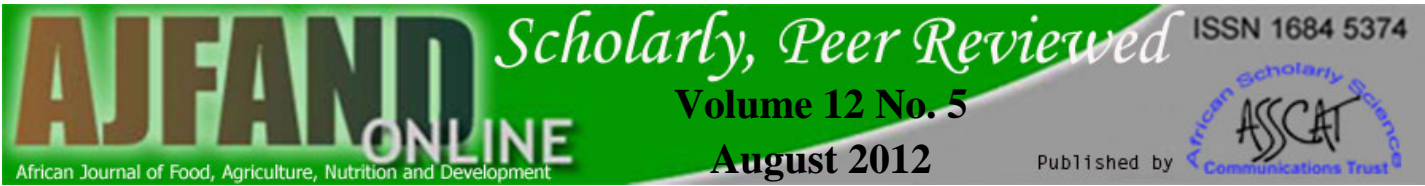

\section{RESULTS}

\section{Types of fast-food consumed}

Figure 2 shows the types of fast-food mainly consumed by people in Kampala district. These included; chips, deep fried chicken, meat, fish, sausages, "chaps", pizzas, kebabs, liver, hot dogs, egg rolls, hamburgers, barbecue steaks, sandwiches and ice cream. Results show that chips (19.1\%), deep fried chicken (14.5\%), sausages (14.1\%), deep fried meat (10.2\%) and “chaps" (10.0\%) were the main fast-food consumed.

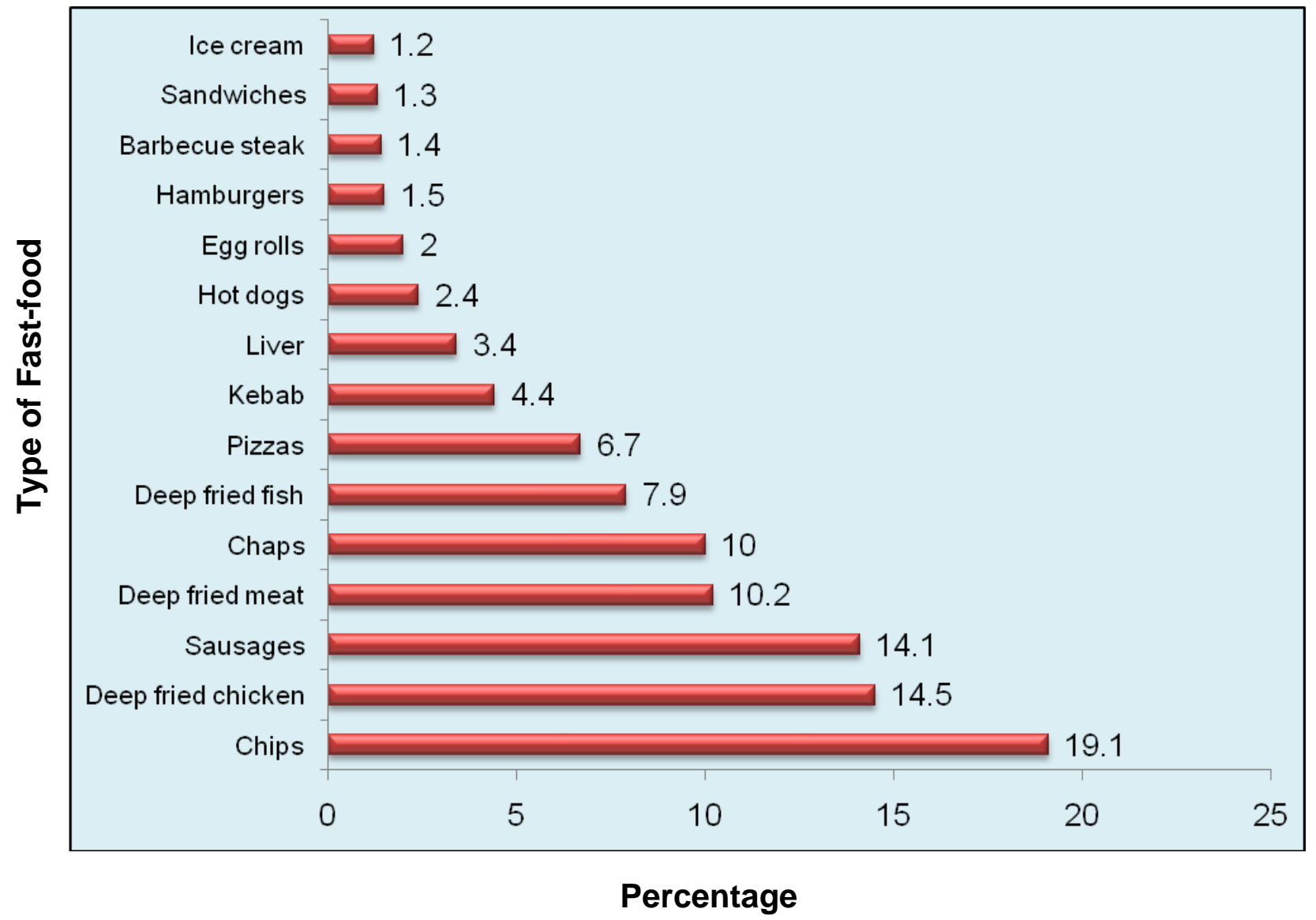

Figure 2: Types of fast-food consumed in Kampala District

\section{Reasons for consuming fast-food}

The study revealed that $90 \%$ of the respondents interviewed consumed fast-food compared to non-consumers (10\%). Results in Table 1 shows that people consumed fast-food for the following reasons: tasty nature (34.5\%), convenience (33.1\%), occasions/social events (17.8\%), children's preferences $(7.3 \%)$ and existence of fastfood in a wide variety (7.3\%). 


\section{Factors influencing the probability of consuming fast-food}

The results of the probit model explaining the decision to consume fast-food are presented in Table 2. Of the nine variables hypothesized, five were significant determinants of the probability of consuming fast-food. These included time spent away from home, education level, disposable monthly income, household size and age. Occupation, distance from work place to restaurant, gender and marital status of respondents were not significant. The effect of time spent away from home and disposable monthly income on fast-food consumption was positive. Age, education level and household size of the consumer were negatively related to fast-food consumption.

\section{Factors influencing the level of expenditure on fast-food}

Results of the second step of the Heckman model (the expenditure equation) are presented in Table 3. Of the five variables hypothesized to influence expenditure on fast-food, four were significant. These included distance from work place to restaurant, household size, education level and disposable monthly income. Gender of the respondent was not significant.

Results show that disposable monthly income and inverse mills ratio were positive and significant while distance from the work-place to the restaurant, education level, household size and income squared had significant and negative effects on fast-food expenditure. The negative effect of income squared implies that income has a nonlinear relationship with fast-food expenditure (Table 3).

\section{DISCUSSION}

\section{Types and reasons for consumption of fast-food}

The many types of fast-food consumed by people in Kampala district suggest greater availability and choice of fast-food products which may also influence their consumption [7]. The taste and convenient nature of fast-food dominated reasons for their consumption. On the other hand, some people consumed fast-food as a way of socializing with friends and family members or during social gatherings while others did so because of their children's preferences [7, 8, 22].

\section{Factors influencing the probability of consuming fast-food}

The significant effect of time spent away from home implies that as people spend more hours away from home, they are more likely to dine out on fast-food so as to save time (Table 2). An increase in time spent away from home by one hour increases the likelihood of consumption of fast-food by $0.5 \%$. These results are consistent with those of other researchers [4, 6, 22, 23] who reported a positive and significant effect of time spent away from home on the participation and expenditure level of FAFH.

Age significantly affects the consumption of fast-food. An increase in consumer's age by one year would decrease the probability of consuming fast-food by $0.2 \%$. This could be due to a high preference for healthier foods as consumers grow older. These results tally with those of other researchers [8, 22, 24] who indicated a negative

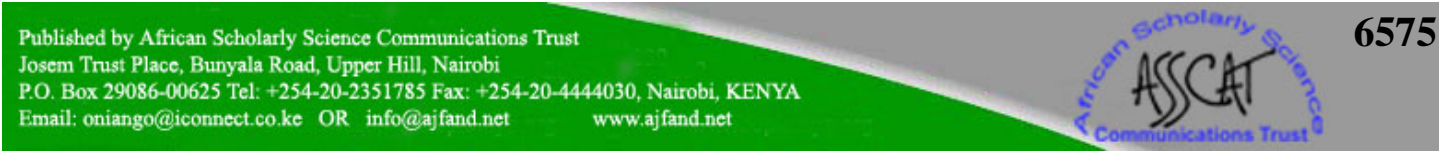


relationship between age of the consumer and fast-food consumption. Thus, consumption of fast-food declines with age.

Fast-food consumption significantly increases with disposable monthly income implying that those with higher incomes are more likely to consume fast-food than those with lower incomes. An increase in disposable monthly income has been reported to encourage both consumption and expenditure on fast-food and FAFH in general $[8,23,25]$. On the other hand, the negative and significant coefficient for the education variable implies that an increase in consumer's education by one year reduces the consumption of fast-food by $0.5 \%$ (Table 2 ). Thus, those who are highly educated are less likely to consume fast-food because education increases their knowledge of nutrition aspects of fast-food, limiting its consumption and shifting to healthier food options. This is consistent with Fanning et al. [24] who showed that educated households are more health conscious and thus have lower consumption of fast-food. On the contrary, other researchers $[6,8]$ found that education had a positive effect on fast-food consumption behaviour; that is, consumption of fast-food increased with their education level.

Consistent with other studies [6, 8, 22], household size had a negative effect on the consumption of fast-food implying that the bigger the household size the lower the probability of consuming fast-food. This means that it is convenient and cheaper for smaller households of fewer people to consume fast-food compared to bigger households.

\section{Factors influencing the level of expenditure on fast-food}

Distance from the work-place to the restaurant had a negative and significant influence on expenditure on fast-food. This means that consumers will spend less on consumption of fast-food if restaurants are located far away from their respective work places. The reason is that consumers increasingly value time and thus will spend on fast-food from conveniently located restaurants [6].

Consistent with previous studies [24], education level of consumers had a negative and significant effect on fast-food expenditure implying that an increase in education level leads to a reduction in the level of expenditure on fast-food. Thus, individuals with higher education level ( $\geq 15$ years spent in school) spend less on consumption of fast-food likely because they understand the importance of health [26] and are more likely to obtain, process, interpret, and apply knowledge that shapes nutritional or dieting practices [27].

Household size negatively affects expenditure on fast-food implying that an increase in household size by one member reduces expenditure on fast-food by UGX 2,147 or USD 0.77 ( 1 USD $=2,785$ UGX as on $12^{\text {th }}$ September, 2011). This is expected because it is more expensive to take a bigger household to a fast-food joint than eating at home.

The results further show that disposable monthly income had a positive effect on fastfood expenditure. As expected, this implies that those with higher incomes spend

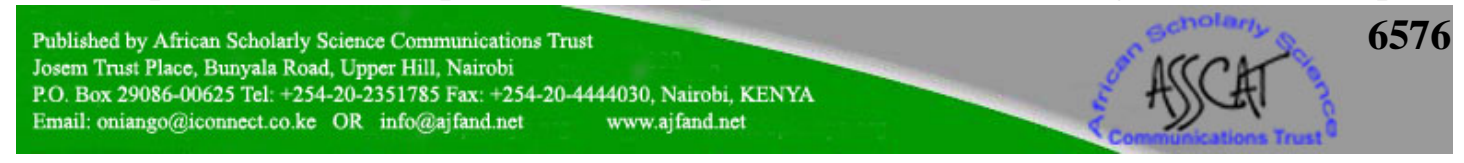


more on fast-food than those with lower incomes. This is consistent with past studies $[6,8,23,25]$ that show trends in income as having a positive and significant impact on FAFH expenditures. The non-linear relationship between income and expenditure on fast-food implies that an increase in income initially leads to an increase in fastfood expenditure; however, beyond a threshold of UGX 240,000, further increase in income leads to a reduction in fast-food expenditure.

The significant effect of the IMR on fast-food consumption implies that an estimation bias would have occurred had the fast-food expenditure been estimated without the consideration of the step-wise decision to consume fast-food.

\section{CONCLUSION}

The main objective of this study was to establish the determinants of consumer participation in the fast-food market in Kampala district. Specifically, the objectives of the study were: to assess the factors influencing the probability of consuming fastfood; and to determine the level of expenditure on fast-food.

Results showed that chips, deep fried chicken, sausages, deep fried meat and "chaps" were the main fast-food consumed in Kampala district. Taste and convenient characteristics of fast-food were the main reasons for consuming them.

Results from the Probit model showed that time spent away from home, education level, disposable monthly income, household size and age of the respondent significantly affect the probability of fast-food consumption while the expenditure model results indicated that distance from work place to restaurant, education level, disposable monthly income, and household size significantly influence consumer expenditure on fast-food.

\section{RECOMMENDATIONS}

The study revealed that there is a high demand for fast-food in an urban setting and this offers market opportunities for Agribusiness firms. They (agribusiness firms) should, therefore, invest in the fast-food sector and produce sufficiently for this market. In addition, fast-food firms should ensure proximity of their products and services to the consumers as convenience greatly influences fast-food consumption.

The study concentrated on socio-economic/demographic determinants of the probability of consumption and expenditure on fast-food by consumers, but it did not study the sources of agricultural products used in the preparation of fast-food. Future research should, therefore, include identification of sources of agricultural products used by fast-food outlets to provide information about the contribution of the fastfood sector to agricultural marketing and farmers' livelihoods in Uganda. 


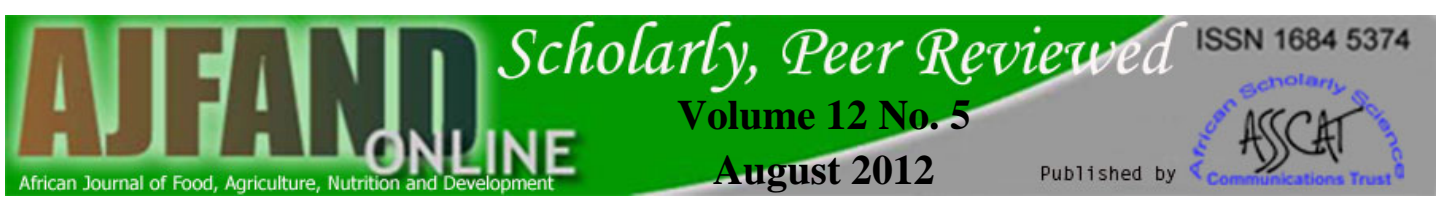

Table 1: Reasons for consuming fast-food

\begin{tabular}{lcc}
\hline Reasons & $\begin{array}{c}\text { Frequency* } \\
(\mathbf{n = 4 3 8 )}\end{array}$ & Percentage \\
\hline Tasty & 151 & 34.5 \\
Convenient or time saving & 145 & 33.1 \\
Occasions/social events & 78 & 17.8 \\
Children's preferences & 32 & 7.3 \\
Wide variety & 32 & 7.3 \\
\hline
\end{tabular}

*Multiple responses

Table 2: Probit model estimates of the determinants of fast-food consumption

\begin{tabular}{lccc}
\hline Variable & $\mathbf{d y} / \mathbf{d x}$ & $\mathbf{Z}$ & $\boldsymbol{\rho}$-value \\
\hline Occupation & 0.005 & 0.50 & 0.615 \\
Distance from work place to restaurant & -0.011 & -1.36 & 0.173 \\
Time spent away from home & 0.005 & 1.66 & $0.097^{*}$ \\
Education level & -0.005 & -1.79 & $0.074^{*}$ \\
Disposable monthly income & 2.080 & 1.84 & $0.066^{*}$ \\
Gender & -0.013 & -1.08 & 0.278 \\
Household size & -0.006 & -1.80 & $0.072^{*}$ \\
Age & -0.002 & -1.86 & $0.063^{*}$ \\
Marital status & -0.009 & -0.68 & 0.497 \\
\hline
\end{tabular}

*, Significant at $10 \%$ 


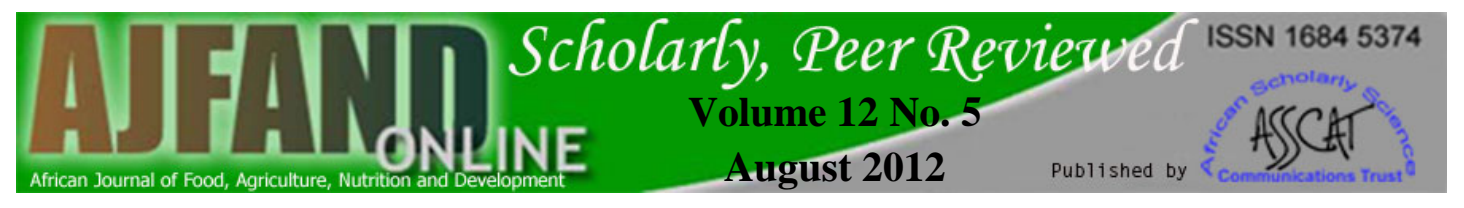

Table 3: OLS model estimates of the determinants of expenditure on fast-food

\begin{tabular}{lrrrl}
\hline Variable & Coefficient & Std. Err. & t-value & $\boldsymbol{\rho}$-value \\
\hline $\begin{array}{l}\text { Distance from work } \\
\text { place to restaurant }\end{array}$ & -7472.802 & 4414.468 & -1.69 & $0.092^{*}$ \\
Household size & -2147.011 & 1143.247 & -1.88 & $0.061^{*}$ \\
Education level & -1529.749 & 626.060 & -2.44 & $0.015^{* *}$ \\
Gender & -1957.028 & 4574.537 & -0.43 & 0.669 \\
Disposable income & 0.050 & 0.005 & 9.63 & $0.000^{* * *}$ \\
Income2 & -4.570 & 1.180 & -3.89 & $0.000^{* * *}$ \\
Inverse mills ratio & 229.451 & 7358.241 & 0.03 & $0.075^{*}$ \\
\hline
\end{tabular}

$*, * *, * * *$ Significant at $10 \%, 5 \%$ and $1 \%$ respectively

OLS - Ordinary Least Squares

Table 4: Correlation Matrix

\begin{tabular}{|l|l|l|l|l|l|l|l|l|l|}
\hline & Occup & Age & Dist & MS & Time & HH & Educ & Income & Gend \\
\hline Occup & 1 & $.267^{* *}$ & .036 & $.180^{* *}$ & .064 & -.003 & $.399^{* *}$ & $.255^{* *}$ & $.139^{*}$ \\
\hline Age & $.267^{* *}$ & 1 & $.018^{* *}$ & $.512^{* *}$ & -.061 & $.289^{* *}$ & $.155^{* *}$ & .066 & $.198^{* *}$ \\
\hline Dist & .036 & .018 & 1 & .059 & -.040 & .030 & .015 & -.107 & .032 \\
\hline MS & $.180^{* *}$ & $.512^{* *}$ & .059 & 1 & -.043 & $.209^{* *}$ & .105 & -.010 & $.220^{* *}$ \\
\hline Time & .064 & -.061 & -.040 & -.043 & 1 & $-.223^{* *}$ & -.057 & $.233^{* *}$ & .042 \\
\hline HH & -.003 & $.289^{* *}$ & .030 & $.209^{* *}$ & $-.233^{* *}$ & 1 & .046 & -.103 & .024 \\
\hline Educ & $.399^{* *}$ & $.155^{* *}$ & .015 & .105 & -.057 & .046 & 1 & -.002 & -.084 \\
\hline Inc & $.225^{* *}$ & .066 & -.107 & -.010 & $.233^{* *}$ & -.103 & -.002 & 1 & .111 \\
\hline Gend & $.139^{*}$ & $.198^{* *}$ & .032 & $.220^{* *}$ & .042 & .024 & -.084 & .111 & 1 \\
\hline
\end{tabular}

** Correlation is significant at 0.01 level (2-tailed)

* Correlation is significant at 0.05 level (2-tailed)

Occup, Dist, MS, HH, Educ, Inc and Gend represent respondent's occupation, distance from restaurant to work place, marital status, household size, education level, monthly disposable income and gender, respectively 


\section{REFERENCES}

1. Clauson A Spotlight on National Food Spending. Food Rev 2000; 23(3): 1517.

2. Kant AK and BL Graubard Eating out in America 1987-2000: Trends and Nutritional Correlates. Pre Med 2004; 38: 243-249.

3. Guthrie JF, Lin BH and E Frazao Role of Food Prepared Away from Home in the American Diet 1977-78 Versus1994-96. J Nutr. Educ and Behav 2002; 34: $140-150$.

4. Ekelund RB and RK Watson Restaurant Cuisine, Fast-food and Ethnic Edibles: An Empirical Note on Household Meal Production. Kyklos 1991; 44(4): 613-627.

5. Jekanowski M, Binkley JK and J Eales Convenience, Accessibility, and the Demand for Fast-food. J Agric and Res Econ 2001; 26(1): 58-74.

6. Stewart $\mathbf{H}$ and ST Yen Changing Household Characteristics and the Awayfrom-home Food market: A censored Equation System Approach. Food Policy 2004; 29: 643-658.

7. Matthews A, Newman C and M Henchion A Double-Hurdle Model of Irish Household Expenditure on Prepared Meals. 2003.

8. Akbay C, Tiryaki GY and A Gul Consumer Characteristics Influencing Fast-food Consumption in Turkey. Food Control 2007; 18: 904-913.

9. Haines PS, Popkin BM and DK Guilkey Methods of Patterning Eating Behaviours of American Women. J Nutr. Educ 1990; 22: 124-132.

10. Biing-Hwan L and E Frazao Nutritional Quality of Foods at and Away from Home. Food Review. US Government Printing Office, Food and Rural Economics Division, Economics Research Service, USDA. 1997.

11. Ochieng H Eating to Death. Sunday Monitor, 109: 1-2. Kampala, Uganda. 2009.

12. Kayemba G The Growth and Development of Fast-food Outlets in Kampala City. Thesis presented for the Award of Bachelor of Tourism, Makerere University, Kampala. 2000.

13. UBOS. Uganda Bureau of Statistics 2010 Statistical Abstract, Kampala, Uganda. 2010.

14. Okoboi G The Marketing Potential of Potatoes in Uganda and Market Opportunities for Rwanda, International Institute for Tropical Agriculture. 2001. 
15. Kennedy G, Nantel $\mathbf{G}$ and $\mathbf{P}$ Shetty Globalization of Food Systems in Developing Countries: A Synthesis of Country Case Studies. FAO Food and Nutrition Paper; 83. 2003.

16. Nakalungi D The challenges of Running Fast-food services in vibrant food industry in Uganda. Thesis presented for the Award of Bachelor of Tourism, Makerere University, Kampala. 2004.

17. Nambaziira $\mathbf{F}$ The Importance of Fast Foods to the Development of Tourist Industry in Uganda. Thesis presented for the Award of Bachelor of Tourism, Makerere University, Kampala. 2005.

18. Namawejje $\mathbf{J}$ Spartial Distribution and Development of Restaurants and Take-a-ways in the Provision of Fast-food Service in Jinja Town. Thesis presented for the Award of Bachelor of Tourism, Makerere University, Kampala. 2006.

19. Heckman JJ Shadow Prices, Market Wages, and Labor Supply. Econometrica, 1974; 42(4): 679-694.

20. Heckman JJ Sample Selection Bias as a Specification Bias. Econometrica1979; 47: 53-161.

21. Baslevent C Self-perceived age categorization as a determinant of the old age boundary. Econ Bull 2010; 30(3): 1994-2001.

22. McCracken VA and JA Brandt Household Consumption of Food-Awayfrom-Home. Am J Agric Econ 1987; 69(2): 274-284.

23. Huang J, Bai J, Wahl IT and BT Lohmar The Determinants of Consuming Food Away from Home: The Role of Hosted meals. 2007.

24. Fanning $\mathbf{J}$, Marsh $\mathbf{T}$ and $\mathbf{K}$ Stiegert Determinants of Fast-food Consumption. Food System Research Group. 2002.

25. Fabiosa JF The Food-Away-from-Home Consumption: Expenditure Pattern in Egypt. Working Paper No 474. 2008.

26. Molitor GTT Food systems: Perspectives on demographics and affluence, food supply, and consumption. Environ Health Perspect 1990; 86: 201-223.

27. Mancino $\mathbf{L}$, Lin $\mathbf{B H}$ and $\mathbf{N}$ Ballenger The role of economics in eating choices and weight outcomes. Washington, DC: U. S. Department of Agriculture, Economic Research Service, Agricultural Bulletin Number 791. 2004. 